\title{
RELEVANCIA DE ALGUNOS CONCEPTOS Y ARQUETIPOS DE C. JUNG PARA LA LABOR PROFESIONAL DE LOS TRABAJADORES SOCIALES
}

\section{ANA M. ${ }^{a}$ HERTOGUE}

Trabajadora Social Jubilada de la «Family Welfare Association» de Londres

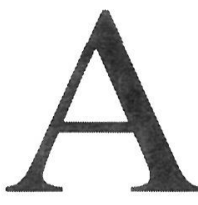

lo largo de su dilatada y fecunda carrera profesional, como psiquiatra y psicoanalista, C. Jung fue descubriendo y elaborando una serie de importantes conceptos que pueden orientar eficazmente la labor profesional de los Trabajadores Sociales y hacer más fecundo su servicio a la sociedad. He aquí, brevemente expuestos, algunos de ellos:

\section{LA «PERSONA»Y LA «SOMBRA»}

En el proceso de llegar a ser un individuo civilizado, según C. Jung, todo ser humano busca una forma de compromiso entre él y la sociedad que le está dictando lo que debería ser. Se origina así la formación de la «persona», entendida en el sentido de máscara. Tal era, en efecto, el nombre que se daba en las tragedias griegas a las máscaras que llevaban los actores, para dar un significado al rol que estaban representando.

Además de esta «persona», en la entidad psíquica de cada hombre y mujer hay también la «sombra», esto es, aquellas partes de sí mismo que considera que son impresentables a los demás. A menudo la «sombra» permanece en el inconsciente personal. Se trata del ser inferior, deseoso de hacer aquellas cosas que no están permitidas. Es el Mr. Hyde del doctor Jekyll. La «sombra» es necesaria para tener una entidad completa, ya que solamente un cuerpo tridimensional tiene una sombra. Esto explica, por ejemplo, que cuando encontramos a alguien cuyo Yo (Ego) es muy parecido a nuestra «sombra», nos podamos sentir irritados, celosos o con sensación de malestar.

Cuando un hombre o una mujer tiene una «persona» demasiado rígida, esto significa que hay una negación excesiva de la «otra cara» de su personalidad, de esos otros aspectos que estuvieron relegados al área individual o que pertenecen al Inconsciente Colectivo. Así, cuando una persona, de repente, explota de rabia o expresa poderosos sen- 
timientos de cariño, se excusa diciendo: «yo no era mí misma», o «no sé de verdad lo que me pasó», etc. Lo que en realidad ocurrió no fue otra cosa que la subida a la conciencia de su «sombra», de lo incontrolable en su ser.

Es esta «sombra» la que aparece en los sueños, personificada por un ser humano muy primitivo o de nivel inferior, con características desagradables o, en suma, alguien a quien uno no quiere.

La «sombra» es también algo más que el inconsciente personal. Es una característica común a toda la humanidad, un fenómeno inconsciente colectivo. Este aspecto colectivo de la «sombra» está expresado por una figura de demonio, de bruja o algo similar. No se puede evitar tener una «sombra»; un ser humano es incompleto sin su «sombra». A modo de ejemplo, se la ve a veces actuar de forma activa en la gran irritabilidad y falta de tolerancia de los «supervirtuosos», algunos de ellos ciudadanos muy respetables que llevan una vida sexual sorprendentemente desviada; o también en los crímenes cometidos en círculos de la alta sociedad donde no tendrían que ocurrir jamás. Todas ellas son manifestaciones de la sombra. Pero si se la reprime demasiado fuertemente, hay peligro de que en el inconsciente adquiera más fuerza y crezca su vigor. Es más visible, también en sus aspectos colectivos, cuando, por ejemplo, hay motines.

Así pues, algunos contenidos del inconsciente de los individuos son comunes a toda una raza o a la humanidad entera. Hay arquetipos comunes a todas las sociedades humanas, que aparecen, a manera de símbolo o temas recurrentes, en los cuentos de hadas, por ejemplo. Hay también instintos comunes a toda la humanidad. Lo más importante es saber que los arquetipos incluyen la figura del Héroe, del Dragón, del Sabio-Anciano, de la Gran Madre, entre otros muchos. Este concepto representa, pues, el vínculo entre la literatura psicoanalítica y el arte, la historia, la religión.

\section{ANIMUS/ANIMA EN LA RAZA HUMANA}

Otro descubrimiento de Jung, que puede ser útil conocer en orden al Trabajo Social, es la existencia, en lo más profundo del inconsciente de un hombre, de un elemento femenino; $y$, en el inconsciente de una mujer, de un elemento masculino. Son lo que se llama el «ánima» del hombre y el «animus» de la mujer.

Si tomamos el ejemplo del hombre, hay que añadir que esta feminidad latente en él es solamente un aspecto de su «ánima», porque en el inconciente de un hombre hay también una imagen colectiva de la mujer, con cuya ayuda comprende la naturaleza de ésta. Pero es solamente la mujer como un fenómeno colectivo, general, la que el hombre percibe de esta manera. La razón de ello es que esta imagen es 
un arquetipo, una representación de la muy antigua experiencia - experiencia milenaria- que un hombre tiene de la mujer; y a menudo esta imagen no representa el ser real de cualquier mujer como un ser individual. Esa imagen, sin embargo, vuelve a ser consciente y real a través de los muchos contactos que tiene un hombre con mujeres, a lo largo de su vida.

El primero y más importante es a través de su madre. Hay hombres que no pueden escapar nunca de su poder fascinante. Se trata de una experiencia muy subjetiva: no sólo es cómo se comporta la madre, sino cómo siente él que ella se comporta, lo que tiene realmente un significado para él.

No es una imagen exacta, sino formada y condicionada por la aptitud interna del hombre para producir la imagen de mujer, el «ánima». Hasta una época tardía, en el transcurso de su vida, esta imagen es proyectada sobre todas las mujeres que encuentra; y esa proyección es la causa que produce tantos malentendidos y fracasos, porque la mayoría de los hombres no advierten que están proyectando su propia imagen interna sobre personas que son, de hecho, muy diferentes de ésta. Y lo mismo ocurre por parte de la mujer, en cuanto proyecta su imagen interna del hombre, su «animus», sobre los hombres concretos que encuentra.

Esta imagen que tiene la mujer del hombre, por la razón de que es también un arquetipo del Inconsciente Colectivo, se reviste de cualidades que continúan apareciendo a través de los tiempos y algunas de cuyas características parecen permanecer de modo constante. El ánima/animus tiene una cualidad que es, en cierta manera, inmortal. A menudo es joven, revestida de un cierto grado de sabiduría; tiene algo de extrañamente significante, es poseedora de una ciencia secreta, de una sabiduría escondida. Muchas veces está vinculada con la tierra o el agua, siendo portadora de un gran poder. Tiene dos aspectos, uno luminoso y el otro oscuro. Presenta, por un lado, una figura pura, buena, de divinidad noble; por el otro, es la prostituta, la seductora o la bruja. Es, por ejemplo, cuando un hombre reprime fuertemente su «ánima», el momento en que desvaloriza, desprecia o desatiende a las mujeres, cuando este aspecto oscuro surge. A veces parece ser un hada o un elfo y tiene el poder de seducir a hombres, atrayéndoles fuera de su casa o de su trabajo. Esta figura aparece constantemente en los mitos y en la literatura como diosa o «femme fatale»; o en cuentos de Hadas, como ninfa, o sirena, o espíritu del agua.

$\mathrm{El}$ «ánima» o «animus» es parte de la personalidad humana. Esto implica el reconocimiento de la existencia de un complejo psíquico semiconsciente que tiene autonomía parcial de funcionamiento.

Otros dos arquetipos que ejercen influencia sobre la vida humana son los del Anciano Sabio y de la Gran Madre. El primero aparece en varias formas; a veces es un rey, un héroe, o un brujo, o un salvador. 
Esta figura puede ser peligrosa, si cree un hombre que tiene esos poderes mágicos; atrae a sus seguidores por razón del poder compulsivo del arquetipo con el cual está revestido.

El arquetipo de la Gran Madre actúa de la misma manera con una mujer. Cree ella que posee una infinita capacidad de amar y de comprender, de ayudar y proteger, llegando a agotarse en el servicio de otros. Pero puede volver a ser muy destructora, insistiendo en que los que entran en contacto con ella son sus «hijos» y, por consiguiente, dependientes de ella, sin recursos propios. Ejerce así una sutil tiranía que puede minar y destruir la personalidad de otros.

\section{EL CARACTER EXTROVERTIDO Y EL CARACTER INTROVERTIDO}

Son éstos otros dos conceptos descubiertos por Jung, útiles en diagnóstico y tratamiento en Trabajo Social y son extremos de un continuum. El extrovertido tiene energía psíquica dirigida hacia el mundo externo y el introvertido más bien hacia el interno. Cada uno tiene una dimensión predominante en las áreas de la sensación, la intuición, el pensar y el sentimiento. Y por ello algunos extrovertidos o introvertidos manifiestan un interés innato más poderoso en relación con objetos y hechos, predominando en ellos la sensación. Otros, en cambio, para descubrir la relación entre objetos, o entre ideas, usan más su intuición. Otras personas perciben la realidad de manera más cerebral, siendo predominante en ellas el pensamiento. Otros perciben a través de sus sentimientos. El tipo inferior, el que se considera menos importante, será uno de los aspectos significativos de su «sombra».

Hay que hacer mención también al hecho de que, para Jung, un «complejo» es un nudo de contenidos inconscientes, forma parte de la «sombra» y tiene una raíz arquetípica y personal. Un complejo puede ser constructivo y creativo, o lo contrario.

\section{LA IMPORTANCIA DE LOS SIMBOLOS}

Jung ve vínculos arquetípicos entre símbolos y sus significados. Los símbolos ejercen una influencia muy poderosa sobre cada área de la vida humana. Por ejemplo, el símbolo del progreso, de la evolución, es uno que da un gran significado a la sociedad moderna, aunque es quizás tan ilusorio y sin valor como la práctica de la alquimia en tiempos pasados. No obstante, comprender la naturaleza simbólica de actuaciones, de regalos, de rutinas, es una de las maneras más útiles de entrar en el mundo de otra persona. 


\section{LA VEJEZ}

Mientras que Freud enfocó toda su atención sobre la infancia de los seres humanos, Jung, que aceptó muchos de sus descubrimientos, no aceptó los orígenes exclusivamente sexuales de la libido. El puso el énfasis sobre otras fases de la vida adulta y para personas de cualquier edad, no quiso verlo todo en términos de sus infancias. Era consciente de que había que ofrecerles nuevas metas en su vida y habló de la crisis en el período medio de la vida (midlife crisis), porque en esos momentos hay un desplazamiento de la visión extrovertida hacia la introvertida. Jung veía la vejez como parte de un proceso de desarrollo y escribió: «El final natural de la vida no es la senilidad sino la sabiduría».

\section{LA INDIVIDUACION}

Este concepto es también muy propio de Jung. Es el término usado para describir el desarrollo personal hacia la integridad total de la personalidad, la integración, y el llevar a la conciencia de la «sombra», de la «persona» y de esas partes que no pertenecen al YO (Ego).

\section{LA RELIGION}

Jung veía la religión como un elemento vital para la integración de la sociedad. La muerte no era para él una derrota, «es el final del hombre empírico y la meta del hombre espiritual», decía.

En suma, Jung insistió, más que Freud, sobre los elementos positivos del mundo psíquico y percibió mejor todas las riquezas ofrecidas a la humanidad, ya sea las del mundo del arte, o de las imágenes, o de la religión como vínculo con el Ser Supremo que le da vida y sentido. 